\title{
Juan de Arfe y su idea de custodia procesional: una maqueta de madera inédita en la catedral de León
}

\author{
Juan de Arfe and his procesional monstrance's idea: a \\ inedit wooden model from the Cathedral of León
}

Patricia ANDRÉS GONZÁLEZ ${ }^{1}$

Universidad de Valladolid

Resumen: El uso de maquetas de madera era habitual en la contratación de las obras de platería de mayor importancia. Permitía que el contratante se hiciese una idea cercana del resultado final, y sobre todo apreciar la arquitectura con mayor pureza, al no contar con los relieves en los que se desarrolla el programa iconográfico. Su realización suele estar especificada en las escrituras de contrato, pero desgraciadamente no han llegado hasta nuestros días muchas de ellas, por lo que esta pieza inédita de la catedral de León supone un interesante hallazgo. Además, su estructura y medidas nos permiten pensar que podría corresponder al destacado artista y teórico Juan de Arfe.

Palabras clave: Platería, Orfebrería, Teoría del arte, Juan de Arfe, Custodia procesional, Maqueta.

ABSTRACT: The wooden models were usual for contracting of the most important silver works. So the contractor could get a closer idea of the final result. The architecture was appreciated in his higher purity, by not having reliefs which develops the iconographic. Its realization is usually specified in the writings of contract, but unfortunately have not survived to this day many of them, so this unreleased piece from the Cathedral of Leon is an interesting finding. Moreover, its structure and measures allow us to think that could correspond to the prominent artist and theorist Juan de Arfe.

Keys words: Silvermith's, Art theory, Juan de Arfe, Processional monstrance, Models.

Juan de Arfe (1535-1603)2, sus obras de

${ }^{1}$ Grupo de investigación reconocido "Arte e iconografía en la Corona de Castilla". Quiero agradecer al profesor Fernando Llamazares el conocimiento de esta maqueta inédita y su asesoramiento en algunos aspectos de este estudio; al igual que las facilidades dadas por el Cabildo Catedralicio de León y en concreto Don Máximo Gómez.

${ }^{2}$ N. ALONSO CORTÉS, Noticias de los Arfes, Madrid, 1951. Centenario de la muerte de Juan de Arfe (1603-2003), Sevilla, 2003. J. M. CRUZ VALDOVINOS, “El platero platería y su labor teórica han sido largamente reconocidos y lo siguen siendo en la actualidad por todos los historiadores del arte, como prueba la amplísima bibliografía publicada

Juan de Arfe Villafañe", Iberjoya, 1983, pp. 3-22. M. C. HEREDIA MORENO, "Juan de Arfe y Villafañe, tratadista de arquitectura y arquitecto de plata labrada", Estudios de platería: San Eloy 2005, Murcia, 2005, pp. 193-212. ÍDEM, "La fortuna crítica de Juan de Arfe y Villafañe", Boletín español de Arte, LXXIX, 315, 2006, pp. 307-332. 
sobre ello. Se ha escrito mucho sobre su producción, especialmente sobre sus custodias procesionales de las catedrales de Ávila, Sevilla y Valladolid o el Museo de Santa Cruz de Toledo, y de las desaparecidas como la de la catedral de Burgos, al igual que sobre su última etapa en la Corte donde realiza otro tipo de piezas. Igualmente, se ha investigado su labor teórica, expuesta en los diferentes tratados que publicó, y también sobre cómo plasma esos ideales en algunas de sus obras. Pero este presente estudio saca a la luz una desconocida maqueta de custodia procesional, conservada en la catedral de León, que responde a las teorías arfianas, viniendo a completar el conocimiento sobre las mismas, al igual que nos muestran una posible obra del "escultor de plata y oro" aunque en esta ocasión de madera.

\section{UNA MAQUETA DE CUSTODIA CONSERVADA EN LA CATEDRAL DE LEÓN}

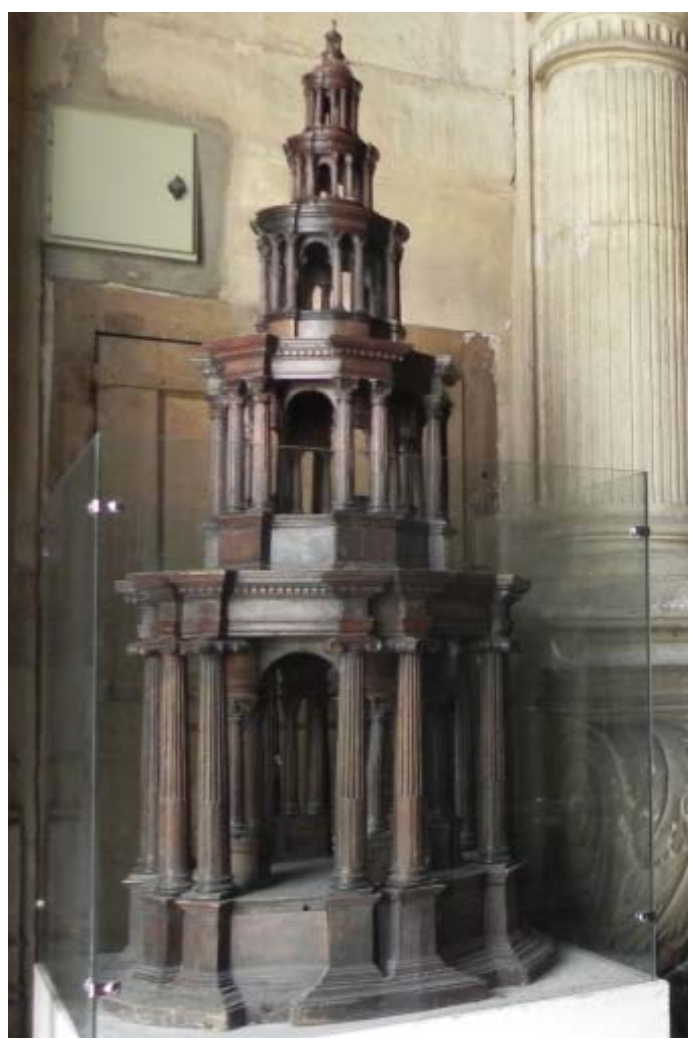

- Fig. 1. Catedral de León. Maqueta de custodia procesional, en madera. Fotografía de la autora con permiso de la Catedral de León.
En una de las capillas, no visitables, del claustro de la catedral de León, que hoy forma parte del Museo, se guarda una interesante pieza de madera, que responde a la tipología de custodia procesional (Fig. 1).

Se organiza como una torre, con cinco pisos decrecientes, de planta circular, más el remate. En cada uno de ellos se reitera el mismo diseño, a base de dos círculos concéntricos: en cada cuerpo encontramos dobles columnas exteriores, que funcionan como peristilos, cuyas basas y entablamentos quiebran el perfil circular utilizado como base, si bien ese movimiento se va suavizando en altura. En el círculo interior utiliza tramos serlianos, arcos de medio punto que arrancan de trozos de dintel, sostenidos por parejas de columnas. Todas ellas son de fuste estriado y en cada uno de los cuerpos cuentan con un alto basamento, cuyas dimensiones disminuyen proporcionalmente. Presenta superposición de órdenes: el inferior es jónico, el segundo corintio, mientras que los otros tres son compuestos.

La maqueta mide un total de $174 \mathrm{cms}$. de alto, desde la parte inferior hasta el remate de la cruz superior ( $\sin$ la cruz, la medida es de $168 \mathrm{cms}$.). El primer cuerpo mide $72 \mathrm{cms}$. de alto, con un diámetro de máximo de 72 cms.; el segundo tiene $41,2 \mathrm{cms}$., con una base de diámetro máximo de $42 \mathrm{cms}$.; la tercera planta tiene una altura de $26,7 \mathrm{cms}$. y una base de 27 de diámetro; la cuarta es de $15,5 \mathrm{cms}$. de alto y $16 \mathrm{cms}$. de base; y la quinta mide $13 \mathrm{cms}$. con un diámetro de 10,5 $\mathrm{cms}$. Se remata con una cúpula y una cruz, que miden en total $6 \mathrm{cms}$., con un diámetro en la base de $13 \mathrm{cms}$.

\section{LA TIPOLOGÍA DE CUSTODIA DE ASIENTO}

Esta pieza inédita presenta una estructura de custodia procesional ${ }^{3}$, tipología surgida en el Gótico, pero que adquiere su

${ }^{3}$ A. GASCÓN DE GOTOR, El Corpus Christi y las custodias procesionales en España, Barcelona, 1916. M. TRENS, Las custodias españolas, Madrid, 1987. C. HER- 
mayor esplendor desde el siglo XVI. Dentro de la misma existen dos variantes: la más frecuente por su número es la denominada como "de pie" u ostensorio manual, la que Juan de Arfe llamó "custodias portátiles" y la conocida como "de asiento" o de torre ${ }^{5}$, menos habitual por sus dimensiones y coste, $\mathrm{y}$ a la que corresponde esta maqueta.

El desarrollo y evolución de las mismas ha sido bien estudiado ${ }^{6}$, caracterizándose además de por sus dimensiones, por ser auténticas microarquitecturas: pequeños templetes realizados en plata, con varios cuerpos escalonados.

Creaciones propiamente hispánicas, un primer grupo de custodias procesionales corresponde al modelo difundido por el artista de origen alemán, pero afincado en España, Enrique de Arfe (1475-1545) ${ }^{7}$, dentro de esquemas góticos. En realidad el tipo ya existía, desde finales del siglo XIV, en los reinos de Aragón y Navarra ${ }^{8}$, aunque

NMARCK, Custodias procesionales en España, Madrid, 1987.

${ }^{4} \mathrm{~J}$. ARFE Y VILLAFAÑE, De varia commensuracion para la esculptura y architectura, Valladolid, edición facsímil 2003, pp. 287-289. M. C. HEREDIA MORENO, "Juan de Arfe...", pp. 193-212.

${ }^{5}$ M. J. SANZ SERRANO, La custodia procesional. Enrique de Arfe y su escuela, Córdoba, 2000.

${ }^{6}$ ÍDEM, "La transformación de la custodia de torre desde los modelos góticos a los renacentistas", en $E l$ arte español en épocas de transición. Actas del IX C.E.H.A., León, 1992, tomo I, pp. 135-136. ÍDEM, La custodia procesional... F. LLAMAZARES RODRÍGUEZ, "Orfebrería eucarística: la custodia procesional en España", en G. FERNÁNDEZ JUÁREZ y F. MARTÍNEZ GIL (coords.), La fiesta del Corpus Christi, Cuenca, 2002, pp. 127-128.

${ }^{7}$ F. J. SÁNCHEZ CANTÓN, Los Arfes: escultores de plata y oro (1501-1603), Madrid, 1920. M. V. HERRÁEZ ORTEGA, Enrique de Arfe y la orfebrería gótica en León, León 1988. ÍDEM, “Los Arfe: teoría y praxis", en La platería en la época de los Austrias, Valladolid, 1999, pp. 91110. F. LLAMAZARES RODRÍGUEZ, “La custodia del Corpus Christi de la catedral de Toledo o la admirable torre eucarística", en Corpus, historia de una Presencia, Toledo, 2003, pp. 287-299.

${ }^{8}$ Documentalmente consta la existencia de otras, pero que hayan llegado hasta nuestros días, debemos no con los rasgos de los que los dota éste. El primero de los Arfe creará para las catedrales de Toledo o Córdoba, unas piezas de grandes dimensiones, en algunos casos con más de dos metros, caracterizadas por la transparencia que permita la contemplación de la Sagrada Forma y un gran número de esculturas de carácter teológico, frente a la opacidad de las piezas de madera, a modo de Arca de la Alianza, que parece que se utilizaban en la festividad del Corpus hasta ese momento.

A partir de mediados del XVI se desarrolla un tipo de custodia renacentista, cuyos principales artífices serán la segunda generación de la misma familia, Antonio de Arfe, y otros plateros como Francisco Becerril $^{9}$ o Juan Ruiz. El modelo es el creado por Enrique de Arfe, pero adaptado a la estética renacentista, con una arquitectura más clara y diáfana, en cuyos vanos se inserta el programa iconográfico.

En esta evolución de la custodia de asiento tiene cada vez más importancia la arquitectura, lo que se confirma en la última etapa, con Juan de Arfe, tercera generación de la saga de plateros, no sólo como su máximo representante, sino también como teórico de la misma ${ }^{10}$.

En su famosísima Varia Commensuración (1a edición incompleta en 1585 y completa dos años más tarde) ${ }^{11}$, desarrolla el

recordar las custodias de Barcelona (1370-90), Ibiza (1399), y Sangüesa (s. XV).

A. LÓPEZ-YARTO, Francisco Becerril, Madrid, 1991.

${ }^{10}$ Además de la Varia, se han consultado otros textos de Arfe: J. ARFE Y VILLAFAÑE, Descripción de la traza y ornato de la custodia de plata de la Sancta Iglesia de Sevilla, publicado en El arte en España, tomo 3\%, Madrid, 1864, pp.174-196. ÍDEM, Quilatador de la plata, oro y piedras, Edición facsímil de Valencia, 1979 (con prólogo de F. Íñiguez Almech).

${ }^{11}$ Existen diversas ediciones actuales de este texto. Hemos consultado J. ARFE Y VILLAFAÑE, De varia commensuracion para la esculptura y architectura, Madrid, edición facsímil 1974 ( $2^{\circ}$ edición, 1978) (con prólogos de A. Bonet Correa), así como la edición facsímil de Ma- 
concepto de la custodia procesional de fines del XVI, sus proporciones y su iconografía ${ }^{12}$.

\section{LA TEORÍA DE JUAN DE ARFE Y LA MAQUETA}

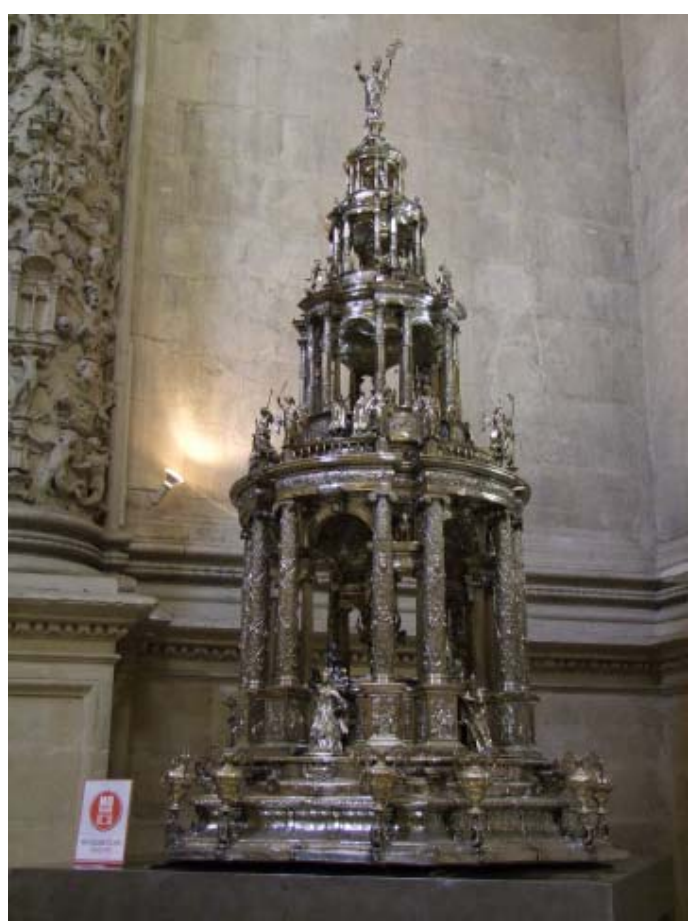

- Fig. 2. Custodia de la Catedral de Sevilla, de Juan de Arfe (1580-87). Fotografía de la autora con permiso de la Catedral de Sevilla.

Los diferentes elementos descritos de la maqueta conservada en León, sus medidas y proporciones, permiten relacionarla con el modelo defendido teóricamente por el último de los Arfe, en la Varia conmensuración ${ }^{13}$ (1587) y con algunas de sus obras, en concreto con la más destacada, la custodia de la catedral de Sevilla ${ }^{14}$, que realiza entre 1580 y 1587 (Fig. 2)

drid, 1978, con prólogo de F. Iñíguez Almech, además de la ya citada edición de Valladolid, 2003, que es la que utilizamos en las siguientes citas.

${ }^{12}$ Ibídem, pp. 287-288.

${ }^{13}$ A. BONET CORREA, Figuras, modelos e imágenes en los tratadistas españoles, Madrid, 1993, pp. 37-104.

${ }^{14}$ I. ROSELL Y TORRES, “La custodia de la catedral de Sevilla", Museo español de antigüedades, T. VIII, 1877, pp. 1-32. M. J. SANZ SERRANO, Juan de Arfe y Villafañe y la custodia de Sevilla, Sevilla, 1978. J. PALOMERO y de la que además se ha conservado, en el museo de la catedral, una maqueta de madera realizada por Antón de Luque.

En primer lugar, sigue la recomendación arfiana de que las custodias procesionales cuenten con cinco cuerpos. Así ocurre en las custodias de Ávila ${ }^{15}$ (1564-1571) y Valladolid ${ }^{16}$ (1587-1591), si bien reduciendo las proporciones, pero sin embargo no la emplea en la sevillana, que se reducen a cuatro.

En todos los cuerpos de la maqueta se utiliza la planta circular, como en la custodia hispalense. Juan de Arfe considera que se pueden usar tanto plantas cuadradas como octogonales, pero termina defendiendo que "siendo redondas son mas claras y de mas capaces cuerpos, como se verán en la que hice para Sevilla". En ello, sigue a Alberti, quien la veía como la forma geométrica más perfecta $^{17}$.

PÁRAMO, "La platería en la catedral de Sevilla”, en $\mathrm{La}$ catedral de Sevilla, Sevilla, 1985, pp. 575-675.

${ }^{15}$ C. J. AYUSO MAÑOSO, Las iconografías de la Custodia de la Catedral de Ávila. Estudio bíblico-litúrgico, 1987 (inédito). N. GONZÁLEZ GONZÁLEZ y A. CRUZ VAQUERO, La custodia del Corpus de Ávila, Ávila, 1993. J. BLÁZQUEZ CHAMORRO, "Custodia de Asiento de Ávila", en La platería en la época de los Austrias Mayores en Castilla y León. Catálogo de la exposición, Valladolid, 1999, pp. 312-315. ÍDEM, La platería de la catedral de Ávila, Ávila, 2003. C. J. AYUSO MAÑOSO, “La custodia procesional de Ávila, de Juan de Arfe (1571)", en F. J. CAMPOS Y FERNÁNDEZ DE SEVILLA (coord.), Religiosidad y ceremonias en torno a la eucaristía: actas del simposium (1/4-IX-2003), Vol. 2, San Lorenzo de El Escorial, 2003 (Devoción y culto general), pp. 803-838.

${ }^{16} \mathrm{~J}$. C. BRASAS EGIDO, La platería vallisoletana y su difusión, Valladolid, 1980. ÍDEM, “En el IV Centenario de Juan de Arfe. Su vida y obra en Valladolid", Boletín. Real Academia de Bellas Artes de la Purísima Concepción, $\mathrm{n}^{\circ}$ 37, 2002, pp. 59-74. ÍDEM, “Juan de Arfe en Valladolid", en Centenario de la muerte de Juan de Arfe (1603-2003), Sevilla, 2003, pp. 79-85. P. ANDRÉS GONZÁLEZ, “Emblemática y Orfebrería en Castilla y León: La custodia de Juan de Arfe en la Catedral de Valladolid", Actas del IV Congreso de la Sociedad Española de Emblemática, Cáceres, 2008, pp 517-534. ÍDEM, Arte, fiesta e iconografía en torno a la Eucaristía: la custodia procesional de Valladolid, Valladolid, 2011.

${ }^{17}$ L. B. ALBERTI, De re aedificatoria, Madrid, 1991. Libro VII, cap. 4 y Libro IX, cap. 5. 
Su uso como única planta en cada uno de los cuerpos de una custodia es poco frecuente. Arfe la emplea por primera vez en la custodia de Sevilla, teniendo como modelo una obra desaparecida, el tabernáculo para el sagrario que en 1565 contrata Juan Bautista Vázquez el Viejo y Francisco de Carona, siguiendo un diseño de Hernán Ruiz el Joven $^{18}$. Lógicamente la maqueta de Luque de ella recoge esa misma disposición, por lo que el parecido con la que presentamos en este estudio es grande.

En la abulense había empleado la planta circular pero alternándola con la poligonal, lo que repite en Valladolid. En la desaparecida custodia de la catedral de Burgos $^{19}$, que realiza al mismo tiempo que la pinciana, debía utilizar también esa alternancia. En cambio, la custodia del Museo de Santa Cruz de Toledo, posible obra del Carmen Extramuros de Valladolid ${ }^{20}$, se separa de estos modelos, con tres cuerpos todos ellos hexagonales, además de unas dimensiones distintas.

Tampoco es habitual su uso en la arquitectura monumental en España y cuando aparece es siempre en espacios parciales como algunas sacristías, relicarios o capillas. Sin embargo, nos consta que se debió experimentar con ella, como preocupación habi-

${ }^{18}$ P. NAVASCUÉS PALACIO, “El Manuscrito de arquitectura de Hernán Ruiz el Joven", Archivo Español de Arte, $\mathrm{n}^{\circ}$ 175, 1971, pp. 295-321. A. BANDA Y VARGAS, El arquitecto andaluz Hernán Ruiz II, Sevilla, 1974. A. J. MORALES, Hernán Ruiz el Joven, Madrid, 1996. M. C. HEREDIA MORENO, "Juan de Arfe Villafañe y Sebastiano Serlio", Archivo español de arte, Tomo 76, no 304, 2003, pp. 371-388.

${ }^{19}$ M. T. MALDONADO NIETO, “La cruz metropolitana de la catedral de Burgos y un nuevo aspecto en la obra de Juan de Arfe", Archivo Español de Arte, tomo LIX, n.o 235, 1986, pp. 304-319. ÍDEM, La platería burgalesa: plata y plateros en la catedral de Burgos, Madrid, 1994. A. BARRÓN GARCÍA, "Juan de Arfe en Burgos", Burgense: Collectanea Scientifica, Vol. 35, no 1, 1994, pp. 249-278 ÍDEM, La época dorada de la platería burgalesa, 1400-1600, Burgos, 1998.

${ }^{20}$ J. M. CRUZ VALDOVINOS, “La custodia de Juan de Arfe del Museo de Santa Cruz de Toledo", Archivo Español de Arte, tomo L, no 197 , 1977, pp. 9-28. tual en el Renacimiento, especialmente en la arquitectura efímera y en la orfebrería ${ }^{21}$. Por ello, esta maqueta cobra valor como muestra de ese interés por la geometría más pura en una realización no teórica.

Otro elemento reiterado en cada uno de los cuerpos de la maqueta son dos círculos concéntricos de columnas (Figs. 3 y 4). Según señala la profesora Carmen Heredia la idea de la doble columnata se puede relacionar con un posible conocimiento por parte de Arfe del templete de San Pietro in Montorio a través de los dibujos de Libro III de Serlio ${ }^{22}$ y que utiliza en la custodia de Sevilla. Tan sólo faltaría en esta maqueta inédita, la presencia de una balaustrada en el primer cuerpo, algo que sí que utiliza en la hispalense. La maqueta sevillana muestra esa misma disposición, e incluye incluso el remate por encima del primer cuerpo.

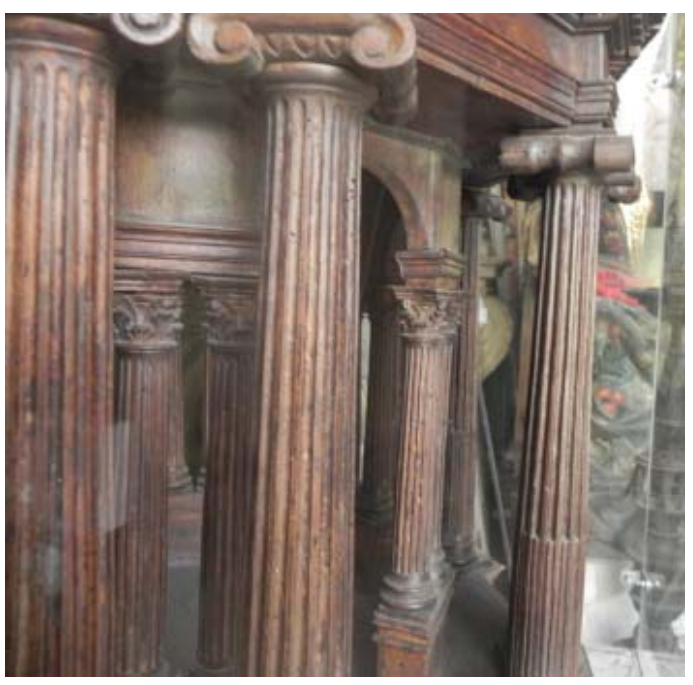

- Fig. 3. Detalle de la maqueta de la catedral de León: doble columnata del $1^{\circ}$ cuerpo. Fotografía de la autora con permiso de la Catedral de León.

${ }^{21}$ M. VARAS RIVERO, "Sobre la orfebrería y la Arquitectura efímera. Apuntes sobre su conexión formal a través de algunos ejemplos sevillanos del siglo XVI y primer tercio del XVII", Laboratorio de Arte, no 18, 2006, pp. 101-121.

${ }^{22}$ M. C. HEREDIA MORENO, "Juan de Arfe Villafañe y Sebastiano Serlio", pp. 371-388. ÍDEM, “Juan de Arfe y Villafañe: tratadista de arquitectura...", pp. 193212. 


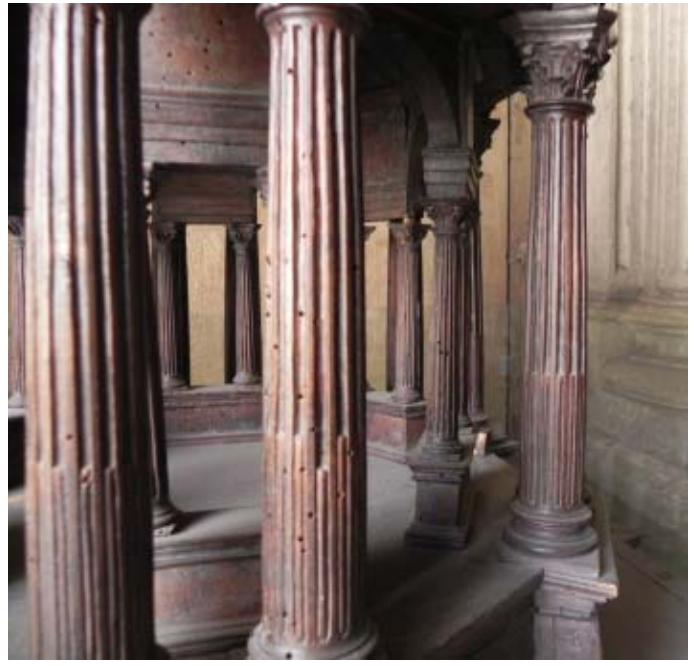

- Fig. 4. Doble columnata del $2^{\circ}$ cuerpo de la maqueta. Fotografía de la autora con permiso de la Catedral de León.

Una primera columnata, la exterior, sigue las proporciones y órdenes que propone Arfe en su teoría; pero en la interior las proporciones se reducen, colocando las columnas sobre altos plintos y reiterando en todos los cuerpos el orden compuesto.

En el espacio interior, utiliza el tramo serliano, parejas de columnas que sujetan arcos de medio punto entre dinteles (Fig. 5). Ya en la custodia abulense, en concreto en el tercer cuerpo, lo emplea, siendo una de las novedades estilísticas introducidas por Arfe respecto a las custodias renacentistas y que muestran un primer conocimiento de Ser$\operatorname{lio}^{23}$. En el cuerpo bajo de Sevilla, y en la fila interior de soportes, reitera el uso de la serliana, incluyendo además unas hornacinas con veneras sobre los tramos adintelados, que recuerdan directamente y una vez más, al modelo dibujado por Serlio de San Pietro in Montorio. También lo emplea en los cuerpos tercero y cuarto de la pieza hispalense, pero sustituyendo las hornacinas por recuadros con óculos. En Valladolid, sin embargo, no vuelve a utilizarlo. En la custodia, sobre el tramo no aparece ningún tipo de elemento decorativo, ni hornacinas ni recuadros; es un simple tramo liso.

${ }^{23}$ Ver nota 22.

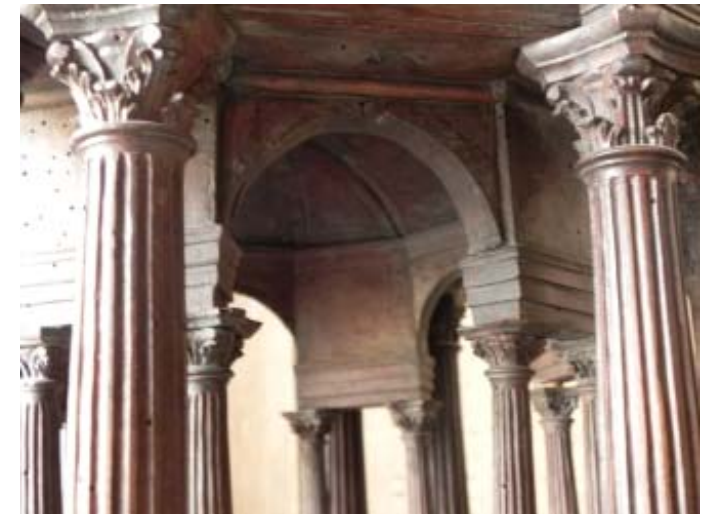

- Fig. 5. Detalle del tramo serliano, en el interior del segundo cuerpo de la maqueta. Fotografía de la autora con permiso de la Catedral de León.

Igualmente, la superposición de órdenes, que se utilizan en esta maqueta es otra de las recomendaciones de la Varia ${ }^{24}$. Éste sí que es un elemento que reitera en prácticamente todas las custodias de plata. En la de Ávila lo hace en los tres cuerpos inferiores, pero en los superiores emplea hermas, balaustres y pilastras. En Sevilla y Valladolid sigue el ideal teórico, al igual que en la desaparecida de Burgos, donde al menos en el contrato estaba previsto.

Las medidas y proporciones de la maqueta de León también se ajustan con gran exactitud al modelo teórico expuesto por Arfe en la Varia. Las recordamos, a pesar de ser conocidas, para aplicarlas en el estudio:

"La Custodia de asiento, quando es de dos varas de alto, poco más, se hace de proporción duple sexquialtera, que es la que tiene el dos con el cinco, comparando el alto con el diámetro del embasamento en todos los cuerpos; porque dividido todo su alto de A. en B. en cinco partes, se dan al asiento dos de ellas de C. en D., y dada una línea obliqua de A. en C. se dan los altos y anchos á las

${ }^{24}$ J. ARFE Y VILLAFAÑE, De varia..., pp. 287-288: “Porque la planta no admite la Órden Dorica, por desnuda de ornato, y malos de poner los triglifos en los Frisos que siguen cortes y resaltos, se toma por primera la Jónica (...). El Cuerpo segundo se hace de Órden Corintia (...). El cuerpo tercero, se hace de Órden Compósita (...). En el cuerpo quarto y quinto van sucediendo con la Órden Compósita con diversos Capiteles, imitando los vestigios antiguos en todo". 
Capillas de que la Custodia se compone de esta manera. Divídese todo el alto en cinco partes, como hemos dicho, y las dos se dan al alto del primer cuerpo de C. en E., y las tres restantes se dividen en otras cinco, y las dos se dan al alto del cuerpo segundo de 2 en F. y las tres se parten en otras cinco, y las dos se dan al cuerpo tercero de 3. en G., y de esta manera, partiendo todas las restantes en cinco, y tomando dos para cada cuerpo, se ponen unos sobre otros en los altos dichos, y el ancho de cada cuerpo se termina con la línea A. C. en los puntos C. 2. 3. 4. 5. 6. L. M. que disminuyen unos sobre otros dos quintas partes de ancho y de alto, el segundo al primero, y el tercero al segundo, y queda cada cuerpo tan alto como ancho" 25 .

Si aplicamos esta proporcionalidad a la maqueta leonesa, encontramos que prácticamente se cumple. Está ligeramente torcida, lo que puede crear el desajuste. Tan sólo en el primer piso no se corresponde exactamente con la proporción, pero a pesar de ello, sí que encontramos una relación exacta entre la altura y el diámetro, lo que se repite en los demás cuerpos.

El primer cuerpo de la maqueta mide $72 \mathrm{cms}$. tanto en el diámetro de la planta como en la altura. De acuerdo con la proporcionalidad citada en la Varia, debería ser ligeramente menor, 69,9 cms. Para los restantes cuerpos, en cambio sí que se cumple la proporcionalidad: $41,2 \mathrm{cms}$. el segundo cuerpo, 26,7 el tercero, 15,5 el cuarto y el quinto 10,5.

Las otras custodias arfianas conservadas no se ajustan a las medidas de dos varas que indica en la Varia, lo que confiere a esta maqueta un mayor valor al ser la plasmación práctica de la teoría de Arfe. Tan sólo la custodia que contrata para Burgos seguía esa dimensión "dos varas y un doceavo de vara" $^{\prime 26}$.

En el texto, indica también cómo deben ser las proporciones de los órdenes de

\footnotetext{
${ }^{25}$ Ibídem, pp. 287-288.

${ }^{26}$ A. BARRÓN GARCÍA, “Juan de Arfe...”, p. 253.
}

las columnas en una custodia de asiento ${ }^{27}$. Una vez más en la maqueta leonesa se cumple exactamente la teoría. En el primer cuerpo, la columna, sin entablamento, mide 56,5 cms., y va sobre un pedestal de $15 \mathrm{cms}$.; por encima se ha colocado un entablamento de 9 cms. Y de modo proporcional se continúa en el resto de los órdenes.

Las mayores variaciones en las custodias arfianas se dan en el alzado de los cuerpos. Utiliza soluciones diferentes tanto en el dibujo de la Varia como en las obras de plata conservadas. También el modelo de la maqueta es distinto.

El primer cuerpo de ésta termina en un entablamento corrido, tan sólo movido en su perfil por los remates de las columnas exteriores (Fig. 6). Esta estructura es muy desigual del modelo teórico dibujado por Arfe en el que aparecen unos frontones rotos (Fig.

${ }^{27}$ J. ARFE Y VILLAFAÑE, De varia..., pp. 287-288: "Porque la plata no admite al Órden Dórica, por desnuda de ornato, y malos de poner los triglifos en los Frisos que sigue cortes y resalto, se toma por primera la Jónica, y para esto se divide el alto del cuerpo primer de C. en E. en catorce partes, la una para el banco primero, y tanto de salida, las tres para el embasamento, ocho para la Coluna, y dos para el Arquitrave, Friso y Cornisa, cuya simetría se sigue por el órden que diximos en la Órden Jónica; y si en este cuerpo se ponen arcos, se da al ancho y claro de ellos la proporción dupla ó sexquialtera, y después de dado el semicírculo que hace la vuelta, se divide el alto que cae á plomo en trece partes, y de ellas se dan al Pedestal, Coluna y Friso sus altos debidos, y se forman otras Colunas ó Pilastrones menores, y esta variedad hace hermoso el Edificio; y no llevando Pedestales se dividen en diez partes, y dan ocho á la Coluna, y dos al Arquitrave, Friso y Cornisa.

El cuerpo segundo se hace de Órden Corintia, y pártese su alto de 2. en F. en quince partes, la una para el banco, y tanto de salida, tres al embasamento, nueve á la Coluna, y dos al Arquitrave, Friso y Cornisa, y su simetría, como en esta órden diximos, y si se ponen arcos, se divide la parte que queda á plomo en catorce partes, y dando las nueve a la Coluna, al Pedestal y Friso las que les caben, se forman en la misma manera; y no llevando Pedestales se parten en once, dando nueve á la Coluna.

El cuerpo tercero se hace de Órden Compósita, y pártese su alto de 3. en G. en diez y seis partes, una para el banco, tres al embasamento, diez á la Coluna, y dos al Arquitrave, Friso y Cornisa, y su simetría, como en esta Órden la tratamos. En el cuerpo quarto y quinto van sucediendo con la Órden Compósita con diversos Capiteles, imitando los vestigios antiguos en todo". 
7). En la custodia de Ávila la estructura es semejante, con un entablamento corrido, pero al ir los remates de los espacios que forman las columnas por delante del mismo, y además con forma de torrecilla, queda oculto.

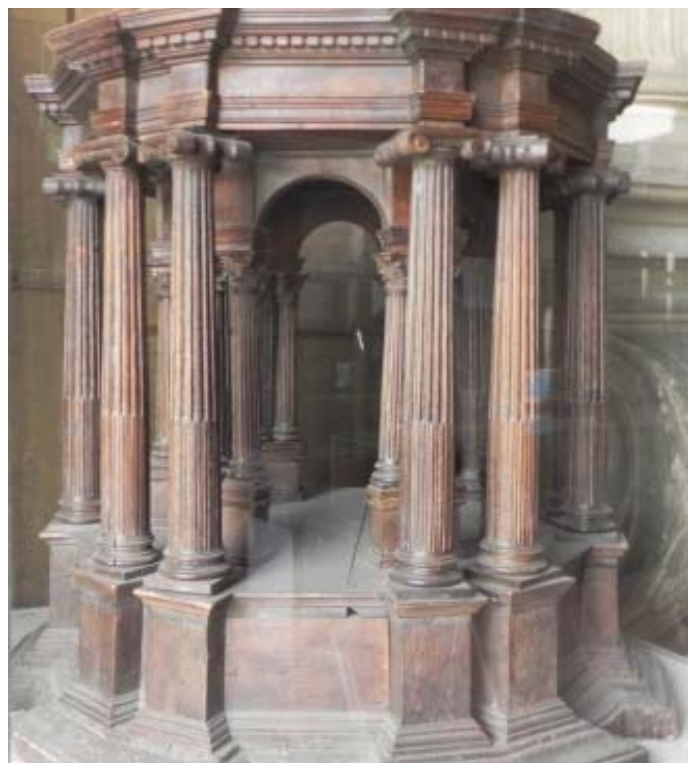

- Fig. 6. Primer cuerpo de la maqueta. Fotografía de la autora con permiso de la Catedral de León.

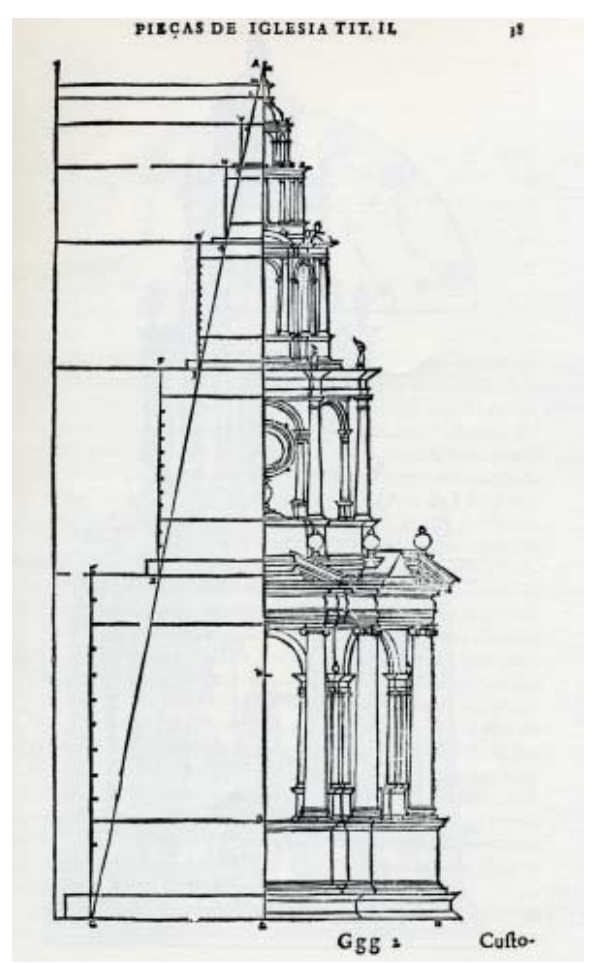

- Fig. 7. Dibujo de maqueta procesional en la Varia.
El mayor parecido lo encontramos con la custodia sevillana, pues en ambas realiza un entablamento curvo, que tan sólo es interrumpido por los intercolumnios creados entre los pares de columnas. La diferencia está en que en la custodia esos intercolumnios se remeten respecto al perfil de la planta, con una estructura que se reitera en el cuarto cuerpo; y en cambio en la maqueta son los entablamentos que se corresponden con cada columna los que sobresalen respecto a dicho perfil. Además, el remate de la custodia es una balaustrada que evoca San Pietro in Montorio, mientras que en la de Valladolid, la planta hexagonal crea un remate quebrado, pero igualmente corrido.

Los alzados de los cuerpos segundo y cuarto de la custodia sevillana coinciden plenamente con los de la maqueta (Figs. 8 y 9), pues en aquellos se modifica respecto al cuerpo inferior el modo en que se quiebra el perfil curvo, haciéndolo en ambos del mismo modo que ocurre en toda la maqueta leonesa. El trozo de entablamento que descansa justo en la vertical de la columna sobresale también del perfil en el segundo cuerpo de la custodia de Ávila, pero en este caso la diferencia está en que no se utilizan pares de columnas. En Valladolid, el segundo cuerpo recurre también a esta misma estructura.

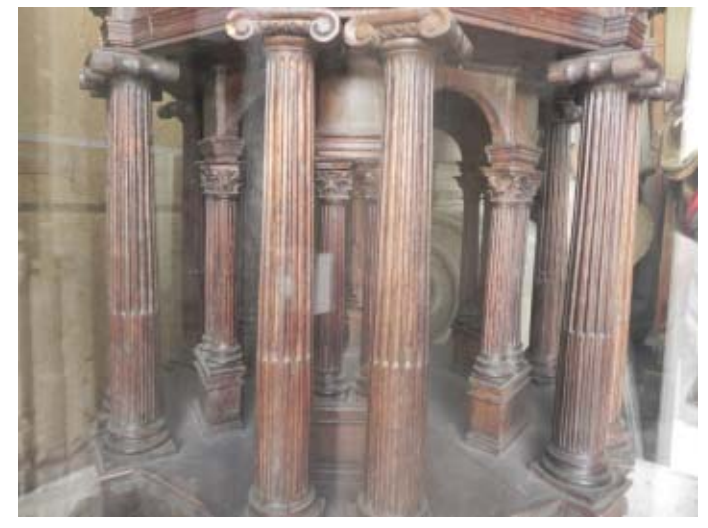

- Fig. 8. Segundo cuerpo de la maqueta. Fotografía de la autora con permiso de la Catedral de León. 


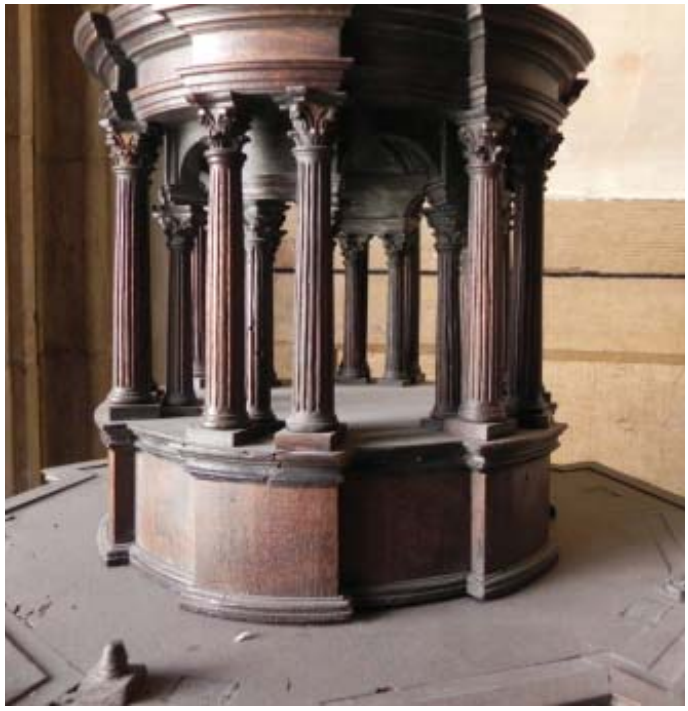

- Fig. 9. Cuarto cuerpo de la maqueta. Fotografía de la autora con permiso de la Catedral de León.

El tercer cuerpo de la maqueta (Fig. 10) es el que presenta una planta más quebrada, pero en alzado reitera el modelo de los otros. Lo mismo ocurre en el cuarto que se remata con una cúpula semiesférica, sobre el que todavía aparece un último cuerpo de pequeñas dimensiones, igualmente columnado (Fig. 11).

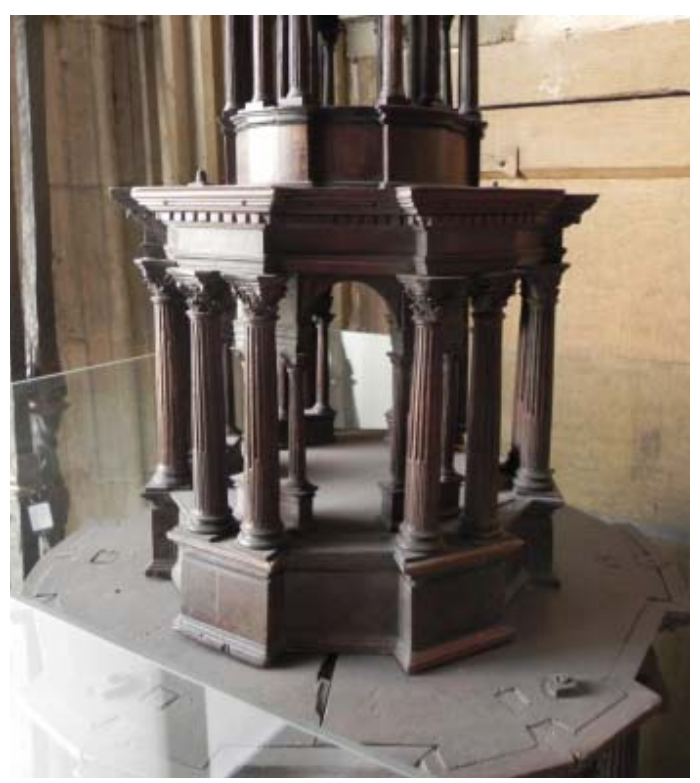

- Fig. 10. Tercer cuerpo de la maqueta. Fotografía de la autora con permiso de la Catedral de León.

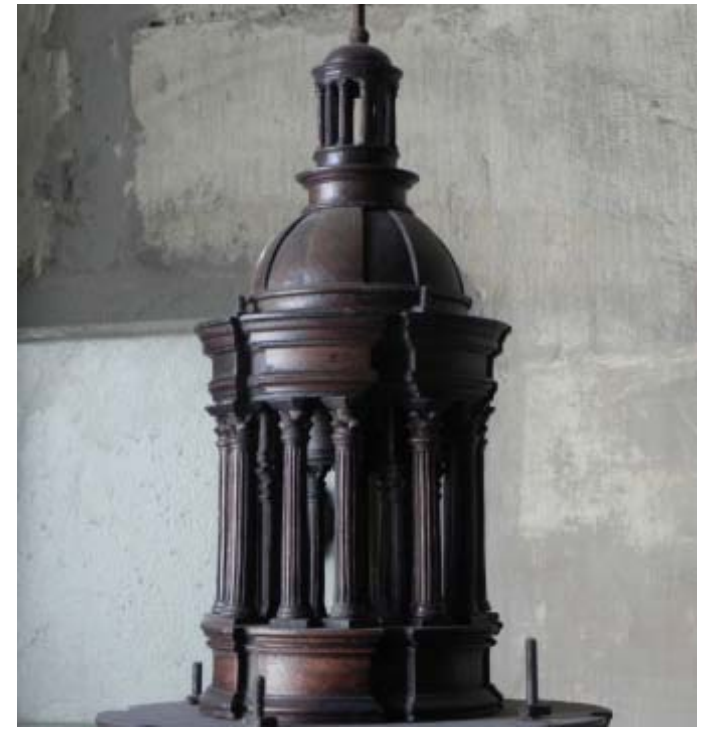

- Fig. 11. Cuarto cuerpo de la maqueta. Fotografía de la autora con permiso de la Catedral de León.

Como ya hemos indicado, en la maqueta leonesa no hay elementos decorativos, lo que permite observar con total pureza el modelo arquitectónico propuesto. Tan sólo destacan las cuidadas estrías de los fustes de columnas y las líneas de imposta que rematan el primer y segundo cuerpo. Las columnas de la custodias abulense van cambiando de orden, pero también de elementos decorativos en su fuste: el tercio inferior con grutescos y el resto estriado en el primer cuerpo; dos tercios, superior e inferior con grutescos en el segundo; estriados con anillos intermedios en el tercero; y hermes, siguiendo a la custodia de Medina de Rioseco de su padre, en el cuarto. En Sevilla, emplea unos fustes con grutescos en la primera planta, tercios superior e inferior con grutescos en la segunda y tercera, y estrías con anillos en el cuarto. En Valladolid, finalmente, no varía tanto, utilizando el modelo abulense, tan sólo eliminando los hermes del cuarto cuerpo, sustituidos por columnas estriadas. La documentación de la custodia de la catedral de Burgos arroja también ese uso de diferentes fustes, jugando con tercios labrados o estriados ${ }^{28}$.

${ }^{28}$ A. BARRÓN GARCÍA, “Juan de Arfe...", pp. 254-255 
También destaca dentro de la calidad de la maqueta el detalle de la parte interior, mostrando cómo sería la cubierta de cada uno de los cuerpos (Fig. 12): unas cúpulas vaídas con motivos decorativos geométricos a base de placas que ocupan lo que fueran las aristas de una bóveda gótica, con un círculo central. No es modelo que coincida con ninguna de las tres grandes custodias de Arfe que han llegado hasta nuestros días. Sin duda, los motivos decorativos explican esa diferencia.

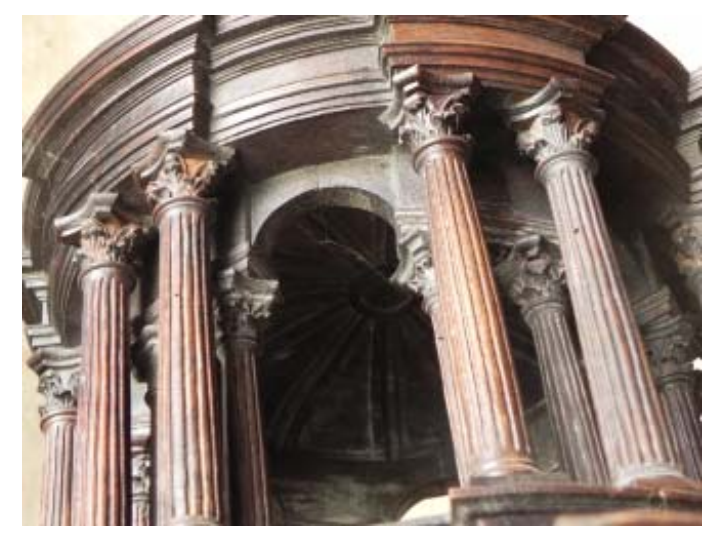

- Fig. 12. Detalle del interior del segundo cuerpo. Fotografía de la autora con permiso de la Catedral de León.

\section{CONCLUSIÓN}

Tras la comparación con elementos de los textos teóricos de Arfe y las piezas conservadas se podría decir que sigue de una forma muy fiel el ideal arfiano. Lo que nos lleva a pensar que se le podría atribuir.

La realización de maquetas consta de modo documental en los encargos de las custodias de Juan de Arfe, y otros muchos plateros. Lo más habitual era presentar plantas y dibujos, pero también este tipo de modelos en madera, aunque no siempre del tamaño final, si no más pequeños.

En la documentación de la custodia de Ávila se menciona como Juan de Arfe había presentado un modelo de madera, además de una traza dibujada. De la sevillana, como hemos citado, se ha conservado la maqueta que realizase Antón de Luque (1580), por en- cargo del "escultor de plata y oro". Es obra que el propio Arfe debió supervisar y por tanto un referente para la maqueta inédita conservada en León. Se trata de una pieza que refleja bien lo que se hará en plata. Los cuatro cuerpos, rematados en una semiesfera, con la ausencia de los relieves, permiten, como se ha señalado, mostrar con claridad el ideal arquitectónico de la pieza ${ }^{29,}$ como ya apuntase el propio Alberti.

Las diferencias entre las dos maquetas desde el punto de vista de proporciones, dimensiones y elementos se han señalado anteriormente. Pero sí que es importante destacar como en la pieza de Luque existe un mayor número de elementos decorativos. Los basamentos de los cuatro cuerpos y los fustes de las columnas están decorados con diferentes motivos geométricos. Sin embargo la leonesa presenta una gran limpieza arquitectónica, los fustes simplemente están estriados en todos los cuerpos.

Lo que resulta extraño es que este modelo de madera de la catedral de León no corresponde a ninguna de las custodias de plata realizadas por Juan de Arfe. El mayor parecido, como hemos indicado, es con la de Sevilla, que tiene su maqueta. Lo más probable es que hubiera sido realizada para alguna custodia que hoy desconocemos. La documentación consultada en la catedral de León no arroja información de si hubo algún encargo al que hubiera podido corresponder.

Sobre las fechas de realización, creemos habría sido realizada al menos durante la estancia de Juan de Arfe en Sevilla, o con mayor probabilidad tras dejar la capital andaluza y trasladarse a tierras castellanas, seguramente en su segunda estancia en Valladolid (1587-1590 y 1592-1596) o en Burgos (1590-1591). La pureza de elementos o la presencia de elementos de influencia serliana, apoyarían esa hipótesis.

\footnotetext{
${ }^{29}$ A. MORALES, "La otra arquitectura", en La arquitectura del Renacimiento en Andalucía: Andrés de Vandelvira y su época, Sevilla, 1992, p. 189.
} 